IP Periodica Polytechnica Mechanical Engineering

62(3), pp. 226-232, 2018

https://doi.org/10.3311/PPme.12065

Creative Commons Attribution (i)

RESEARCH ARTICLE

\section{Coupling between Welding Conditions and Thermal Cycling for Identification of the Mechanical Heterogeneity of a Weld Joint}

\author{
Fatima Zohra Messabih $^{1^{*}}$, Benattou Bouchouicha ${ }^{1}$
}

Received 08 February 2018; accepted after revision 12 April 2018

\begin{abstract}
The analyses device safety subject to pressure is based on the prediction at break junctions used for the design of this type of devices. The harmfulness analysis of existing defects on these devices makes indispensable the study of the rupture in these components. Various characterization tests (tensile tests, fatigue tests and tensile strength tests) were carried out at room and low temperatures on plates welded end to end and for the different directions of sampling.

An estimate of the toughness in the three areas of a weld joint was made by passing from resilience to toughness in the ductile-brittle transition zone of materials. The temperature range of the tests was to provide measurements of the toughness the lower bearing to the beginning of the transition curve. The purpose of this work is to study the state both mechanical and microstructural aspects of the welded junction. The diagnoses used made it possible to deduce that the small thickness of the $H A Z$, makes the machining of the specimen difficult. Thereby, a mechanical simulation of the $H A Z$ by registration of the thermal cycle that this area undergoes was necessary to be able to reproduce it and compare it with the actual HAZ.
\end{abstract}

\section{Keywords}

rupture, welded joint, resilience, toughness, tear

\section{General introduction}

The different oil pipes are made of manganese carbon steel tubes (grade A48-AP) assembled by welding. The breaking process in these pipes results from a ductile tear mechanism and not a brittle fracture [1-5]. The concepts of fracture mechanics and more particularly the global approaches are used to analyze the severity of defects in these welded joints. The heat affected zone HAZ is a privileged zone for the appearance of flaws and the requirement in terms of security for this type of junction. It is therefore essential to study the damage in these areas.

The conducting pipeline is a mechanically welded construction, thus the weldability of the steels of the tubes has repercussions on the cost of production and on the reliability of driving [6-8]. It should be noted that these are hundreds of kilometers of welds made on the construction sites of pipes. Thus, any significant change in the composition of the steel or dimensions of the tubes requires new technical measurements, technology and many precautions to obtain reliable weld joint.

The primary concern of the manufacturer must be the definition of welded joints that make it possible to overcome the pressure loads with a maximum of safety. It is necessary to carry out the welding at the least cost, while taking into consideration the increase in the amount of metal to be deposited according to the increase of the dimensions of the pipes, the use of new steels with a more and more complex chemical composition and the difficult conditions of execution of site assembly welds [9-12]. The most important modifications of the structure and properties of the base metal resulting from heating and cooling in the area adjacent to the cord are: the decrease in plasticity and resilience while the increase the tendency to creating the cold and hot cracks [13-14]. The characteristic feature of steels tubes of the main lines is the tendency to cold crack formation during welding. These cracks are most often formed on the part adjacent to the weld seam either in the heat affected zone HAZ or more particularly in the binding area ZL. With the increase of the thickness of the walls, the tendency to cold cracking increases and this requires the increase of the preheating temperature. The increase of the latter is in this case a function of the chemical composition, the strength category and the thickness of the walls of the tubes.
${ }^{1}$ Laboratory LMSR, University Djilali Liabes Sidi Bel Abbes,

PB 89 ITMA Sidi Bel Abbes, Algeria

*Corresponding author, e-mail: messabihfz@yahoo.fr 
So a microstructural study of the different zones of a weld joint is necessary, and to complete it by a mechanical behavioral analysis is indispensable. As a result, a reproduction of the HAZ by mechanical simulation is an adequate solution to describe the behavior of different parts of this area.

\section{Experimental study}

\subsection{Material used}

The material used in our study is an A48AP steel used in the construction of the pipeline [2]. The process is arc welding carried out according to the API1104 standard, This welding mode has been qualified according to a PQR (Record Qualification Procedure) which includes all tests such as (visual inspection, radiography, hardness, microscopy, traction, folding). The chemical composition and the mechanical characteristics of the base metal are given respectively in Tables 1 and 2 .

Table 1 Chemical Composition of A48AP Steel

\begin{tabular}{ccccccccc}
\hline $\mathrm{C} \%$ & $\mathrm{Si} \%$ & $\mathrm{Mn} \%$ & $\mathrm{Cr} \%$ & $\mathrm{Cu} \%$ & $\mathrm{~S} \%$ & $\mathrm{Ni} \%$ & $\mathrm{Ti} \%$ & $\mathrm{Fe} \%$ \\
\hline 0.08 & 0.236 & 1.243 & 0.136 & 0.02 & 0.01 & 0.002 & 0.016 & 98.15 \\
\hline
\end{tabular}

Table 2 Mechanical properties of steel A48AP

\begin{tabular}{ccccccc}
\hline Feature & $\begin{array}{c}\mathrm{E} \\
(\mathrm{MPa})\end{array}$ & $\begin{array}{c}\mathrm{Re} \\
(\mathrm{MPa})\end{array}$ & $\begin{array}{c}\mathrm{Rm} \\
(\mathrm{Mpa})\end{array}$ & $\mathrm{n}$ & $\mathrm{k}$ & $\mathrm{A} \%$ \\
\hline A48AP & 203000 & 414 & 525 & 0.05 & 578 & 25 \\
\hline
\end{tabular}

\subsection{Mechanical characterization}

\subsubsection{Tensile tests}

For the mechanical characterization of the weld, the standard tensile test specimens were taken in the longitudinal direction according to the standard (NF EN 100002-1), we used three (03) samples in each condition (base metal, weld metal and ZAT) were tested to determine tensile properties. The mechanical characteristics obtained are given in Table 3.

Table 3 Mechanical characteristics in the three zones of the weld

\begin{tabular}{lcccccc}
\hline & $\begin{array}{c}\mathbf{E} \\
(\mathbf{M P a})\end{array}$ & $\begin{array}{c}\mathbf{R e} \\
(\mathbf{M P a})\end{array}$ & $\begin{array}{c}\mathbf{R m} \\
(\mathbf{M p a})\end{array}$ & $\mathbf{N}$ & $\mathbf{k}$ & $\mathbf{A \%}$ \\
\hline BM & 203000 & 297 & 499 & 0.401 & 980 & 28 \\
FM & 190000 & 465 & 560 & 0.508 & 1009 & 30 \\
HAZ & 183000 & 480 & 631 & 0.320 & 836 & 35 \\
\hline
\end{tabular}

The conventional yield strength in the HAZ (480 MPa) is significantly higher than the yield strength in the other areas of the weld joint (MF: $465 \mathrm{MPa}$ and MB: $297 \mathrm{MPa}$ ). As for the tensile strength of the base metal is lower $(499 \mathrm{MPa})$ than in the other two zones (MF: $560 \mathrm{MPa}$ and HAZ: $631 \mathrm{MPa}$ ). We note that all the values of the apparent yield stress and the tensile strength are higher than the allowable minimum values (manufacturer data). A conventional and rational yield strength limit is generally higher in the HAZ than in the MF feed metal, which is higher than that of the base metal.

\subsubsection{Cracking tests and measurements \\ 2.2.2.1 Test Specimens used}

The cracking tests were conducted to ambiant air on CT50 test specimens of $08 \mathrm{~mm}$ in thickness in accordance with ASTM-E-647 (Fig. 1).

For the filler metal (MF) and the thermally affected area, specimen collection is shown in (Fig. 2).

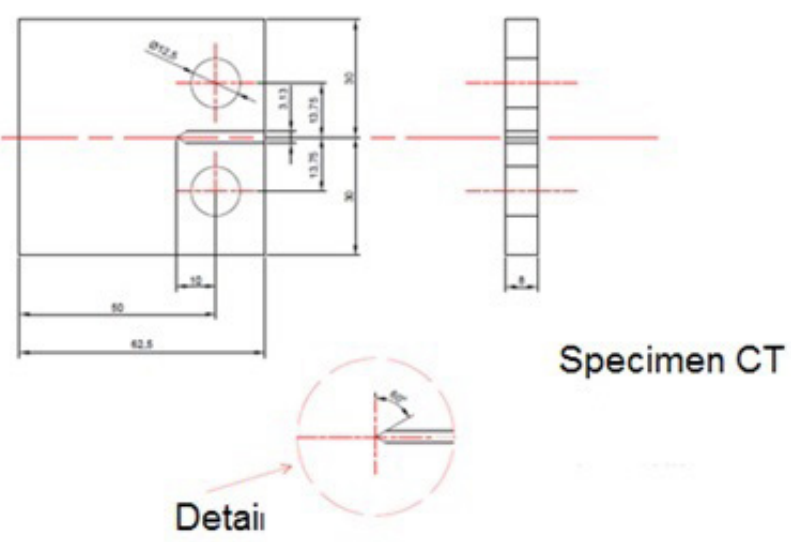

Fig. 1 Geometry and dimensions of CT specimens used for cracking tests
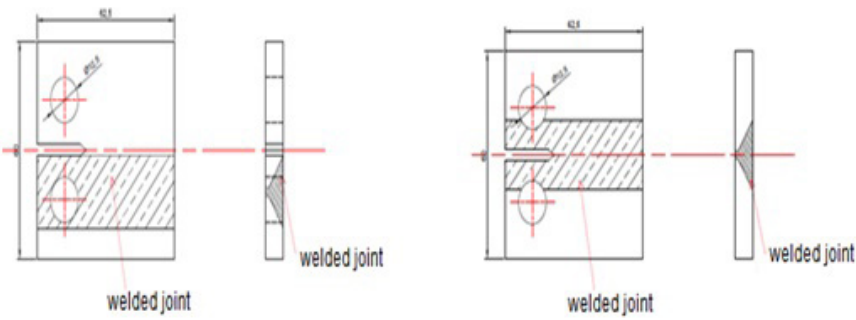

Fig. 2 CT specimen taken from the welded zones

The stress intensity factor $\mathrm{K}$ in the case of a CT geometry is given by the following relation (ASTM Standard E 399):

$$
K=\frac{P}{B \sqrt{W}} f(\alpha) .
$$

Where:

$P:$ is the applied load $[\mathrm{N}]$.

$W$ : is the width of the specimen from the loading axis [m].

$B$ : is the thickness of the specimen [m].

$\alpha=(a / w): a$ : is the crack length.

$f(a / w)$ : is a function of convenience that takes a different form.

$$
\begin{aligned}
f(a / w)= & 29.6(a / w)^{1 / 2}-185.5(a / w)^{3 / 2}+655.7(a / w)^{5 / 2} \\
& -1017(a / w)^{7 / 2}+638.9(a / w)^{9 / 2} .
\end{aligned}
$$




\subsubsection{The crack growth rate}

For the processing of experimental data, a method based on an incremental polynomial method was used. This method uses the smoothing of a series of successive points by a polynomial whose growth is monotonous in this interval of seven points. The equation of the smoothed curve has the following form:

$$
\begin{gathered}
\frac{d a}{d N}=\frac{b_{1}}{C_{2}}+2 b_{2}\left(\frac{N_{i}-C_{1}}{C_{2}{ }^{2}}\right) \\
a_{i}=b_{0}+b_{1}\left(\frac{N_{i}-C_{1}}{C_{2}}\right)+b_{2}\left(\frac{N_{i}-C_{1}}{C_{2}}\right)^{2}
\end{gathered}
$$

$\mathrm{b}_{0}, \mathrm{~b}_{1}$ and $\mathrm{b}_{2}$ : are Regression parameters determined by the least squares method in a range of seven points.

$$
C_{1}=\frac{1}{2}\left(N_{i-3}+N_{i+3}\right) C_{2}=\frac{1}{2}\left(N_{i+3}-N_{i-3}\right) .
$$

\subsubsection{Results and discussions:}

The results obtained from the cracking speed in the various test specimens are represented in Fig. 3 and 4. The curves of the cracking speed present an almost rectilinear look on a large part of the explored domain which can be represented PARIS law' of the form [15-16]:

$$
\frac{d a}{d N}=C(\Delta K)^{m}
$$

The results obtained in the three zones are shown shown in Table 4.

Table 4 Paris' law in the different zones studied

\begin{tabular}{lc}
\hline Designation & Law of Paris \\
\hline $\mathrm{BM}$ & $\mathrm{da} / \mathrm{dN}=7.83 \mathrm{E}^{-8} \Delta \mathrm{K} 2.4$ \\
$\mathrm{MF}$ & $\mathrm{da} / \mathrm{dN}=2.54 \mathrm{E}^{-12} \Delta \mathrm{K} 6.1$ \\
$\mathrm{HAZ}$ & $\mathrm{da} / \mathrm{dN}=4.25 \mathrm{E}^{-9} \Delta \mathrm{K} 3.4$ \\
\hline
\end{tabular}

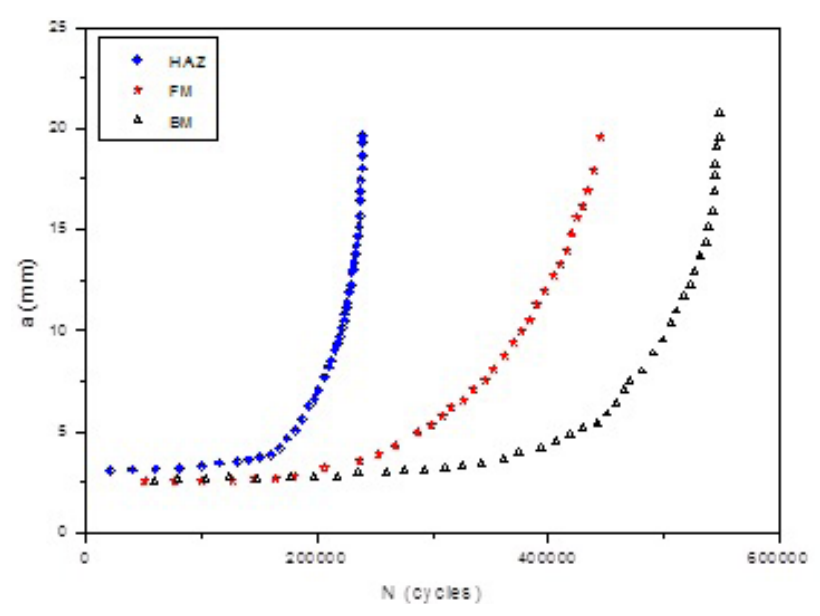

Fig. 3 Extension of the crack according to the number of cycles for the three zones studied

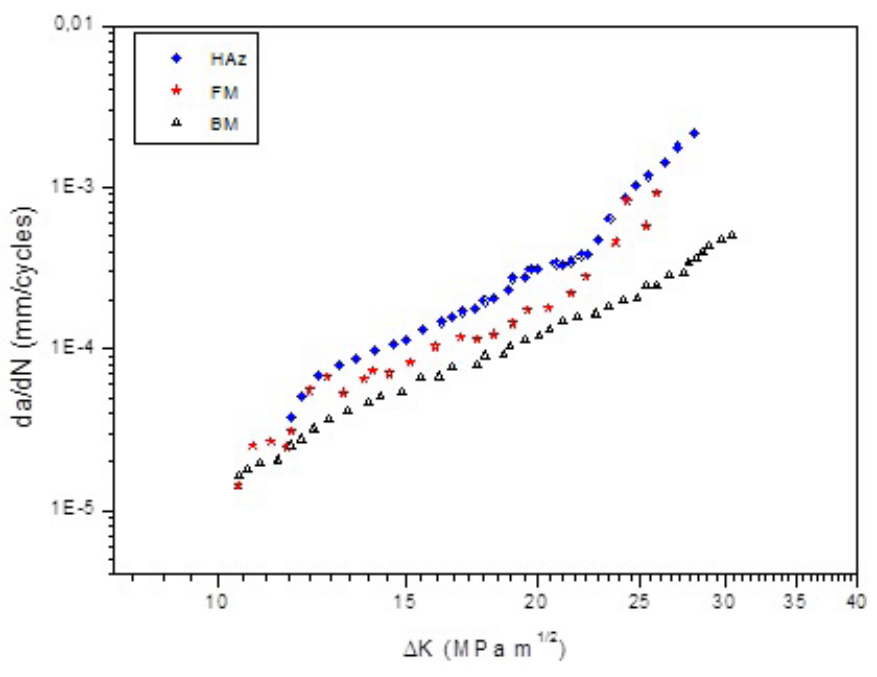

Fig. 4 Evolution of the cracking rate as a function of $\Delta K$ for the three zones studied

For low levels of $\Delta K$ a slight difference is generally observed between the HAZ and the MB base metal. However, the gap between these speeds increases when $\Delta K$ increases to four times the value. This phenomenon is encountered in the case of carbon steels including the API X60 [17-20].

For both types of steels it is noticed that the crack did not deviate from its initial plane (direction of propagation), which leads us to conclude that the weld was good and the choice of filler metal which has a yield strength greater than that of the base metal was adequate.

\subsubsection{Estimate of toughness}

\subsubsection{Preparation of the specimens}

The estimate of the toughness was made from the correlations from resilience tests. These correlations are valid only for the resilience tests carried out on standard $10 \times 10$ dimensions specimens cut in $\mathrm{V}$ the direction of sampling and the dimensions are given in Fig. 5.

To properly locate the notches of the specimens on the zones studied, the welded parts have been mechanically polished to the paper (1000), then a chemical attack with iron perchloride was performed to show the different areas of the weld (Fig. 6).

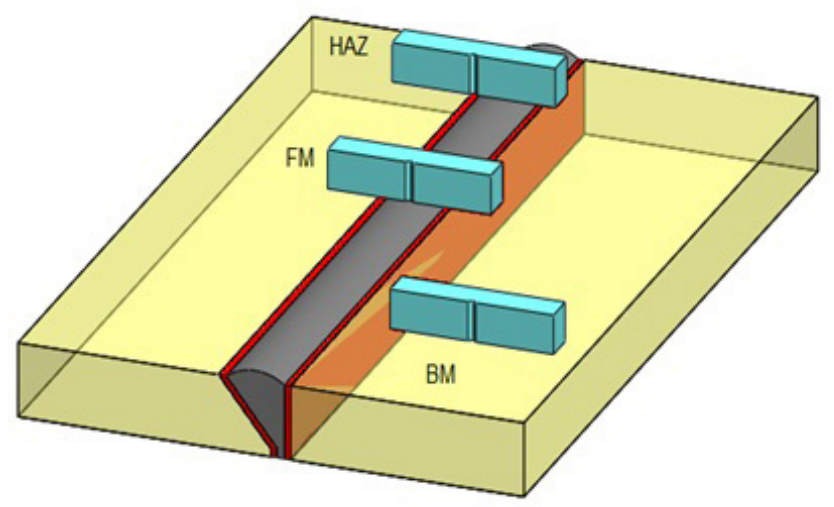

Fig. 5 Sampling direction of the test specimens in the weld zones. 


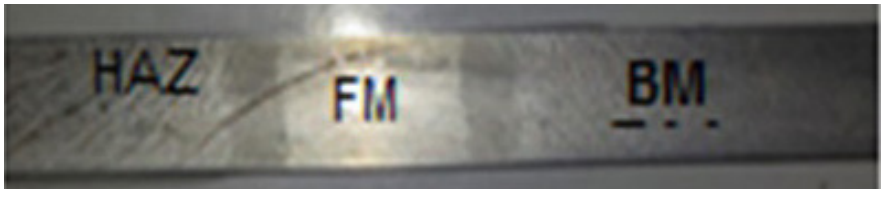

Fig. 6 Schematization of the chemical attack $(\mathrm{Fe} \mathrm{Cl} 3)$ to appear the zones of the welding.

\subsubsection{Test conditions}

The temperature range tests were taken to make possible measurements of the toughness from the bottom to the beginning of the transition curve. For each temperature and each zone, three test pieces were used. The liquid refrigerant used to lower the temperature of the specimens is nitrogen associated with alcohol mixed in a calorimeter (Fig. 7). For heating of the specimens we used an oven, and the measurement of the temperature was made using a digital thermometer.
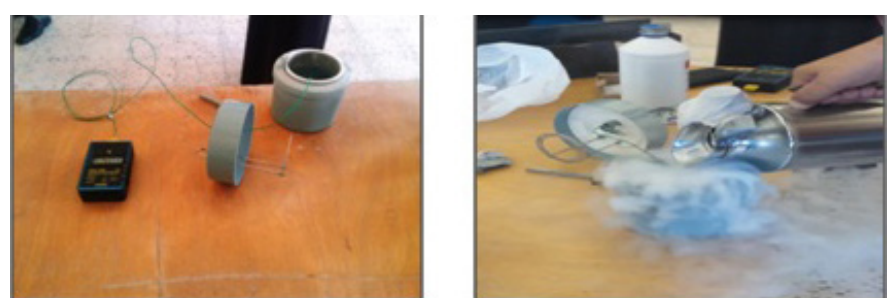

Fig. 7 Cooling System Using Nitrogen

\subsubsection{Correlation resilience tenacity}

The correlation used allows to determine the tenacity at the desired temperature and select the level of probability at break. This correlation takes into account the thickness of the product and on the transition temperature T27J. The expression $\mathrm{xx}$ is applicable to a wide range of steels and validated for different thicknesses.

$$
K_{m a t}=\frac{820 \sqrt{K V}-1420}{B^{1 / 4}}+630 .
$$

Kmat: estimated tenacity $\left(\mathrm{N} / \mathrm{mm}^{3 / 2}\right)$.

B: Thickness of the material for which an estimate of Kmat is required (mm).

$\mathrm{KV}$ : Resilience to the temperature for which it is determined the tenacity $(\mathrm{J})$.

\subsubsection{Results and discussion}

The results obtained are presented in (Fig. 8) and the following conclusions have been drawn.

Overall, the weakest resilience corresponds to the specimens for temperature ranges below $-20{ }^{\circ} \mathrm{C}$.the resilience appears to increase to room temperature $\left(20^{\circ} \mathrm{C}\right)$ and remains virtually unchanged, or a slight rises for temperatures up to $70^{\circ} \mathrm{C}$. The range between $\left(-20^{\circ} \mathrm{C}\right.$ and $\left.20^{\circ} \mathrm{C}\right)$ characterizes the transition temperatures, which are as follows:

For MB the ductility plateau stabilizes before $0{ }^{\circ} \mathrm{C}$ and therefore we speak of stable ductility. On the other hand for the HAZ

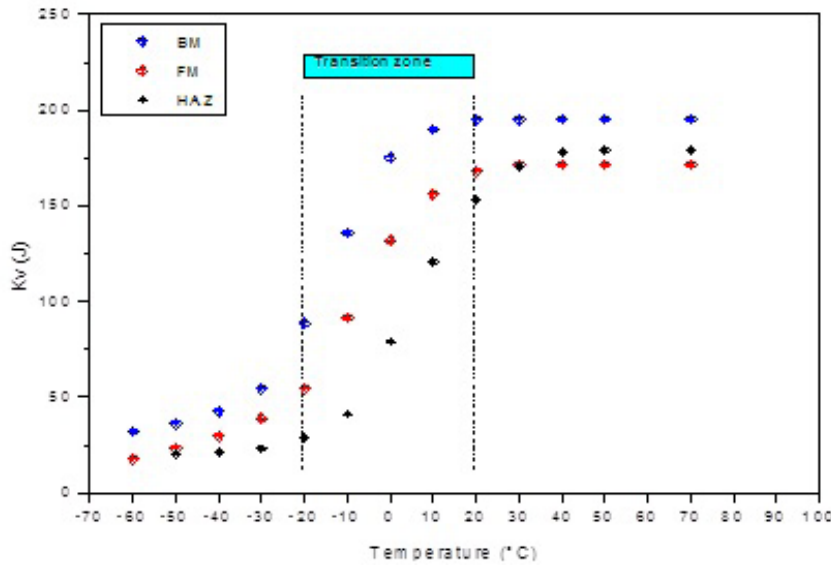

Fig. 8 Resilience curve of the three zones (BM, FM and HAZ)

this transition passes with a hook of Pre-stabiliion HAZ which gives this zone a less stable behavior than the base metal. This phenomenon indicates that there is a change of structure. The molten metal MF lies between the two configurations, this transition is very remarkable in the graphs of micro-hardness filiations.

The results of the toughness presented by (Fig. 9) are obtained by correlation and by introducing an uncertainty factor (distributed according to a Weibull distribution law, (law of the minimum) in the Wallin's correlation. It is noted that for low temperatures a stable average tenacity for the three zones. In the transition phase. We notice a logical evolution but inversely proportional to the laws of behavior of the three zones which characterizes steels working under pressure. From $0{ }^{\circ} \mathrm{C}$ the tenacity values stabilize, with higher values in the base metal (BM) than for the molten metal (FM), with less values for the HAZ. Therefore the parameters used by Wallin for Weibull distribution law appear reasonable [21].

\section{Metallographic examination}

Weld it's establishing a connection or a metallic continuity, however the welded space does not present a homogeneous structure. Indeed localized fusion heating and cooling who

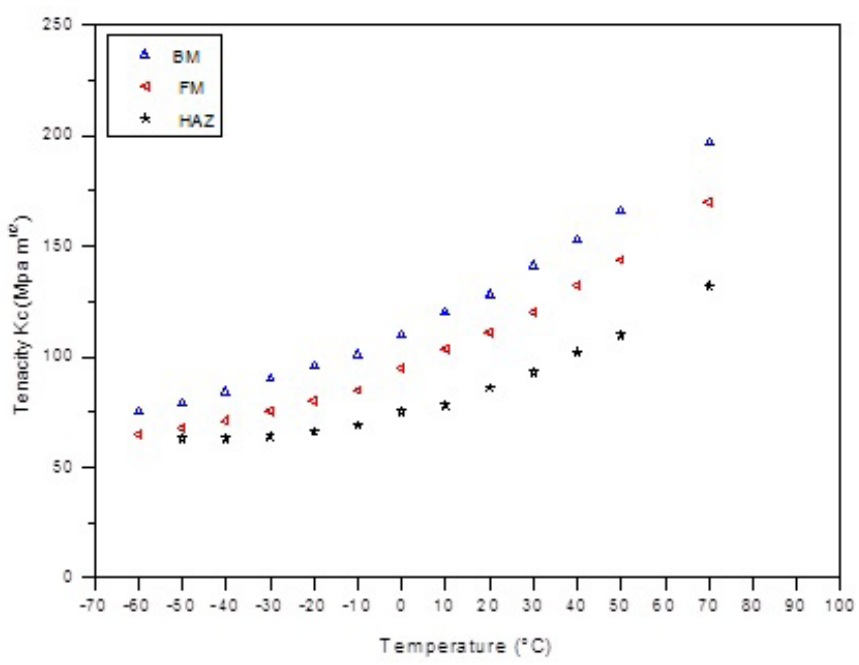

Fig. 9 Tenacity curve of the three zones (BM, FM and HAZ) 
followed have trained various structures. To put in evidence a structure or process to metallographic examinations. After successive polishing the sample is attacked with a reagent at basis of ferric chloride and water (for macroscopic examination) and at basis of Nutric Acid and Alcohol for microscopic examination.

The microscopic examination is performed at ugly of a scope to observe in a way very thin, the structures in an area very localized.

The transformations suffered by the HAZ are not simulable to the heat treatments applied to steels. In fact after a welding operation, there is appearance of the bainite and the ferrite intergranular in the zone of junction and the zones of transformation. The Fig. 10 shown the difference of structure in all three areas.

- Zone BM: The observation shows that there is presence of ferrite and ferrite-pearlite (Fig. 11).

The modification of the microstructure in the welding area is caused by the superposition of the thermal cycle resulting in each welding pass. This thermal cycle is the cause of microstructural transformations base metal (BM), who is transforming thus in thermally affected zone $\mathrm{HAZ}$ or in connection zone. The Figures $\mathrm{X}$ and $\mathrm{Y}$, represent the maximum temperatures recorded by the thermocouples at each welding cycle. Thus the equivalent cycles are determined to be able to simulate this HAZ mechanically.

- MF area: In the last pass of the MF, the provisions ranges ferritic and constituents carburized comparable to ferrite presented a disposition marked related to solidification. The Observation shows the presence of a dendritic structure with islands (ferrite-perlite) Fig. 12.

- Zone HAZ: This zone has a heterogeneous structure variation. The Fig. 13, shows that the structure is ferrito-pearlitic (globular). In the area near the melting line we find an overheated structure with an aspect and a rather special disposition of the ferrite also present islets of bainite in separate slats by ferrite (Fig. 14).
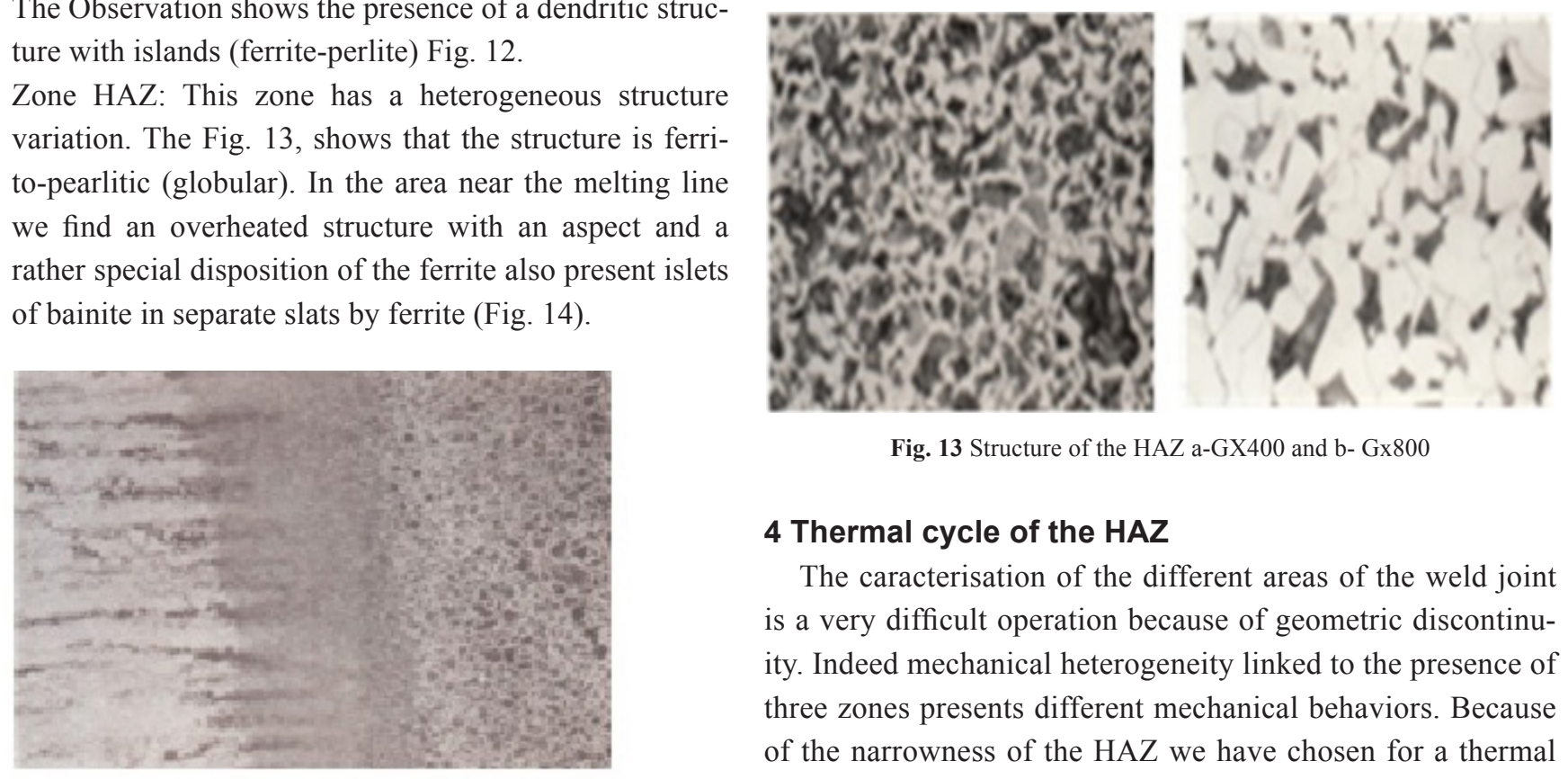

Fig. 13 Structure of the HAZ a-GX400 and b- Gx 800

\section{Thermal cycle of the HAZ}

The caracterisation of the different areas of the weld joint is a very difficult operation because of geometric discontinuity. Indeed mechanical heterogeneity linked to the presence of three zones presents different mechanical behaviors. Because of the narrowness of the HAZ we have chosen for a thermal simulation of the specimens intended for characterization. The goal of this manipulation is to raise the thermal cycle in the different areas to reproduce later the HAZ on the base material without refilling the plates. The modification of the micro-

Fig. 10 Presence of the three zones of the weld joint structure in the welding area is caused by the superposition of 


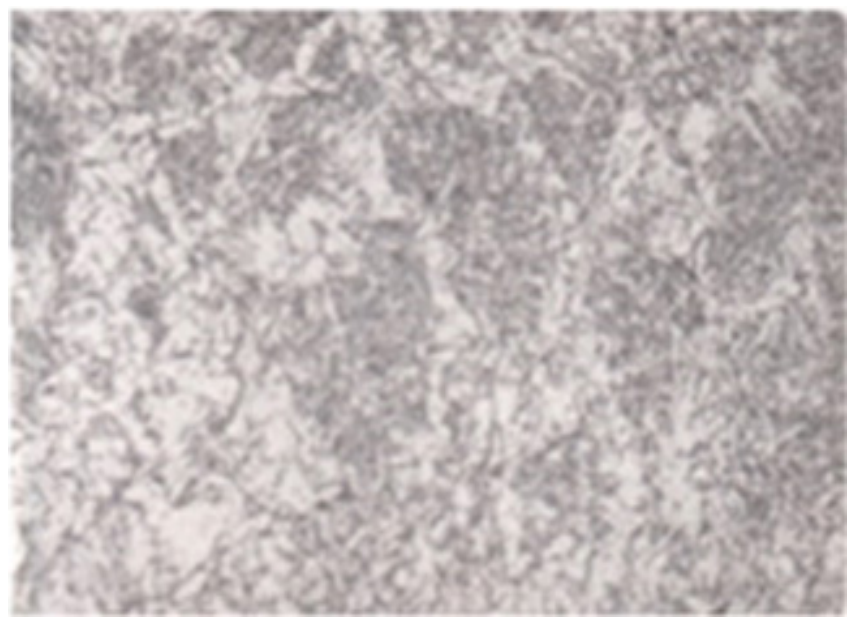

Fig. 14 Structure of the HAZ (connection zone) GX200

the thermal cycle resulting in each welding pass. This thermal cycle is the cause of microstructural transformations base metal (BM), who is transforming thus in thermally affected zone HAZ or in connection zone. The Figs. 15 and 16, represent the maximum temperatures recorded by the thermocouples at each welding cycle. Thus the equivalent cycles are determined to be able to simulate this ZAT mechanically.

For validation of the results by mechanical tests, of the test pieces (pull-ups and micrographs) were taken directly from base metal. The characterization tests and micrographic observations conducted on the simulated ZAT, show that there is a similarity between the two HAZ (real and simulated). We observe an acceptable agreement between the mechanical characteristics of the two HAZ (Table 5), and the Fig. 17, present almost identical appearance of the two microstructures. Indeed, we observe the same provision of the ferrite than observed on the actual HAZ.

Table 5 Comparison between the mechanical characteristics of the HAZ (real and simulated)

\begin{tabular}{lcccccc}
\hline & $\begin{array}{c}\mathbf{E} \\
(\mathbf{M P a})\end{array}$ & $\begin{array}{c}\mathbf{R e} \\
(\mathbf{M P a})\end{array}$ & $\begin{array}{c}\mathbf{R m} \\
(\mathbf{M p a})\end{array}$ & $\mathbf{A \%}$ & $\mathbf{k}$ & $\mathbf{N}$ \\
\hline HAZ & 183000 & 297 & 499 & 28 & 1009 & 0.508 \\
SHAZ & 180000 & 300 & 505 & 20 & 970 & 0.6 \\
\hline
\end{tabular}

\section{General conclusion}

This work allowed determining experimentally the mechanical characteristics as well as resistance to ductile tear at room temperature of base metal (BM), Molten Metal (MF) and Heat Affected Area (HAZ) taken from a welded joint made under conditions representative of industrial manufacturing. The profile of the thermal cycle undergoing in the HAZ was established by a mechanical simulation which made it possible to reproduce the characteristics of this zone on the base metal.

In terms of mechanical characterization, the weakest toughness corresponds to specimens for temperature ranges below $-20{ }^{\circ} \mathrm{C}$. The resilience appears to increase to room temperature $\left(20^{\circ} \mathrm{C}\right)$

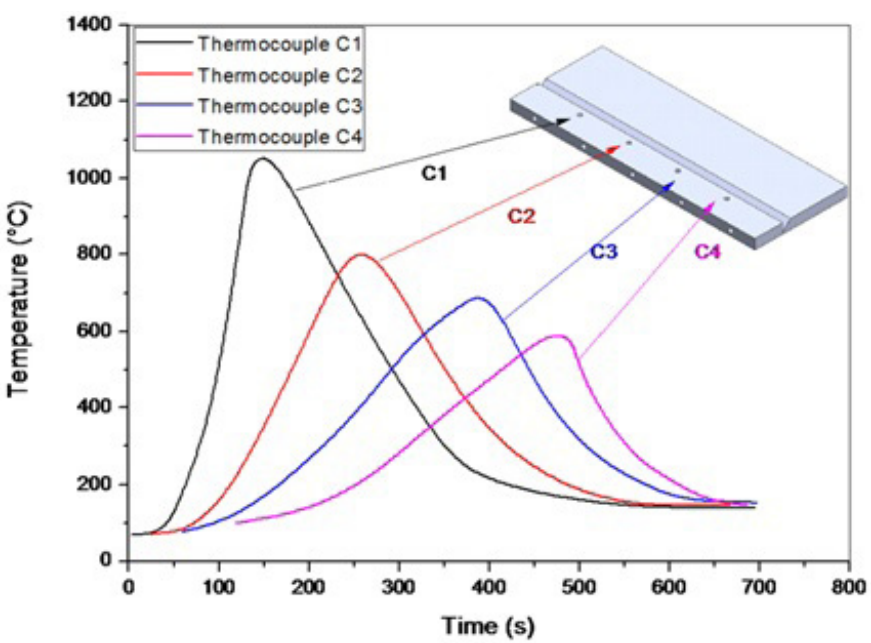

Fig. 15 Temperature evolution as a function of welding time: face thermocouples

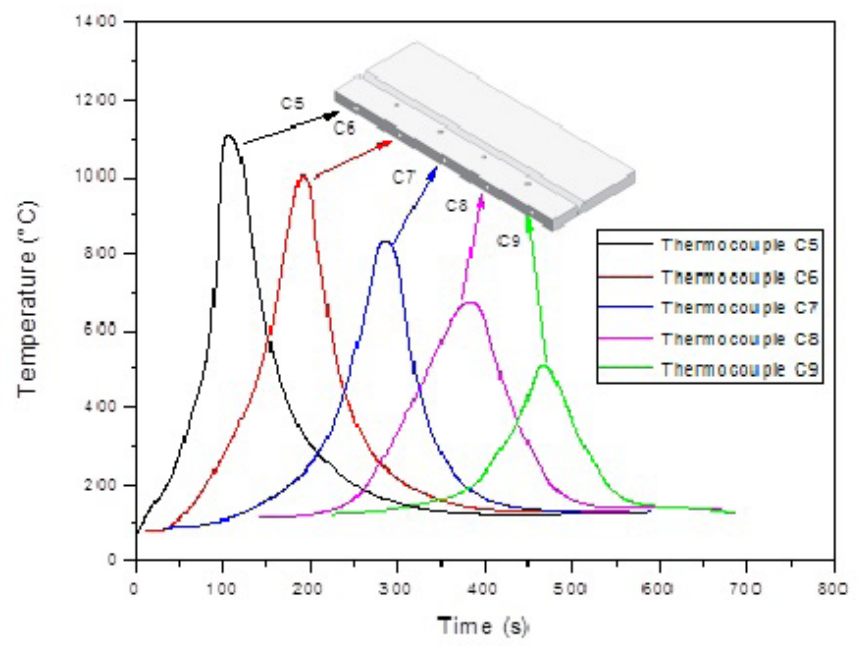

Fig. 16 Temperature evolution as a function of welding time: lateral thermocouples
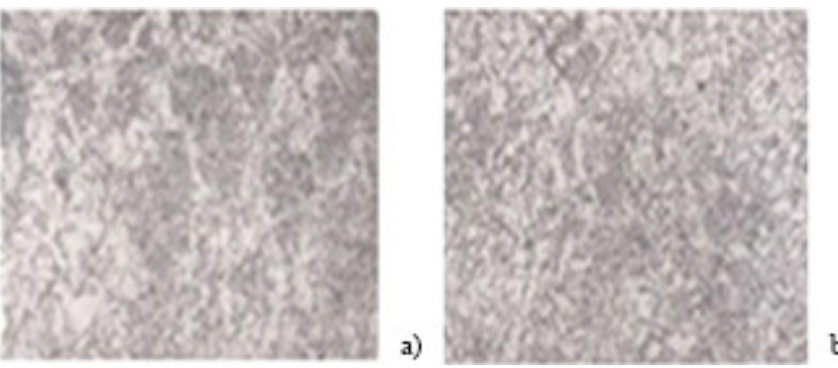

Fig. 17 Structure of the actual HAZ a) and simulated HAZ b) G x 200

and remains practically unchanged with a slight rise for temperatures up to $70^{\circ} \mathrm{C}$. For the $\mathrm{HAZ}$ (real or mechanically simulated) the transition brittle-ductile goes through a pre-stabilization hook which gives this zone a less stable behavior than the base metal. This phenomenon is justified by a change of structure.

The thermally affected zone has a heterogeneous structure variation, this structure is ferrito-pearlitic (globular). In the area near the melting line there is an overheated structure with islands of lapped bainite separated by ferrite. 


\section{References}

[1] Kaddour, B., Bouchouicha, B., Benguediab, M., Slimane, A. "Modeling and optimization of a cracked pipeline under pressure by an interactive method: design of experiments." International Journal on Interactive Design and Manufacturing (IJIDeM). pp. 1-11, 2017.

https://doi.org/10.1007/s12008-017-0385-0

[2] Slimane, A., Bouchouicha, B., Benguediab, M., Slimane, S. A. "Contribution to the Study of Fatigue and Rupture of Welded Structures in Carbon Steel-A48 AP: Experimental and Numerical Study." Transactions of the Indian Institute of Metals. 68, pp. 465-477. 2015.

https://doi.org/10.1007/s12666-014-0477-5

[3] Mazari, M., Bouchouicha, B., Zemri, M., Benguediab, M., Ranganathan, N. "Fatigue crack propagation analyses based on plastic energy approach." Computational Materials Science. 41(3), pp. 344-349. 2008.

[4] Benguediab, M., Bouchouicha, B., Mokhtar, Z., Mazari, M. "Crack propagation under constant amplitude loading based on an energetic parameters and fractographic analysis." Materials Research. 15(4), pp. 544-548. 2012. https://doi.org/10.1590/S1516-14392012005000072

[5] Alioua, A., Bouchouicha, B., Zemri, M., Imad, A. "Effect of Filler Metal Mechanical Properties on Fatigue Behaviour Welded Joints." Transactions of the Indian Institute of Metals. 71(4), pp. 977-984. 2018. https://doi.org/10.1007/s12666-017-1231-6

[6] Reda Taha, M. M., Xiao, X., Yi, J., Shrive, N. G. "Evaluation of flexural fracture toughness for quasi-brittle structural materials using a simple test method." Canadian Journal of Civil Engineering. 29(4), pp. $567-$ 575. 2002.

https://doi.org/10.1139/102-044

[7] Aissani, M., Bassir, D. H., Benkedda, Y. "Thermal Simulation and Experimental Characterizations of Aeronautic Stainless Steel Welded by TIG Process." International Review of Aerospace Engineering. 1(5), pp. 481-488. 2008.

[8] Alberg, H., Berglund, D. "Comparison of plastic, viscoplastic, and creep models when modelling welding and stress relief heat treatment." Computer Methods in Applied Mechanics and Engineering. 192(49-50), pp. 5189-5208. 2003.

https://doi.org/10.1016/j.cma.2003.07.010

[9] Chen, B., Peng, X. H., Fan, J. H., Sun, S. T. "A viscous-elastoplastic constitutive equation incorporating phase transformation with the application to the residual stress analysis for welding process." Journal of Materials Processing Technology. 205(1-3), pp. 316-321. 2008. https://doi.org/10.1016/j.jmatprotec.2007.11.114

[10] Coret, M., Calloch, S., Combescure, A. "Experimental study of the phase transformation plasticity of 16MND5 low carbon steel under multiaxial loading." International Journal of Plasticity. 18(12), pp. 1707-1727. 2002. https://doi.org/10.1016/S0749-6419(01)00067-5

[11] GuoMing, H., Jian, Z., JianQang, L. "Dynamic simulation of the temperature field of stainless steel laser welding." Materials \& Design. 28(1), pp. 240-245. 2007.

https://doi.org/10.1016/j.matdes.2005.06.006
[12] Cui, Z. Q., Yang, H. W., Wang, W. X., Yan, Z. F., Ma, Z. Z., Xu, B. S., $\mathrm{Xu}, \mathrm{H}$. Y. "Research on fatigue crack growth behavior of AZ31B magnesium alloy electron beam welded joints based on temperature distribution around the crack tip." Engineering Fracture Mechanics. 133, pp. 14-23. 2015.

https://doi.org/10.1016/j.engfracmech.2014.11.004

[13] Herny, E. "Caractérisation mécanique et étude des mécanismes de vieillissement thermique et thermomécanique de l'acier inoxydable martensitique 15-5PH, soudé par faisceau d'électrons." (Mechanical characterization and study of the mechanisms of thermal and thermomechanical aging of $15-5 \mathrm{PH}$ marten $\neg$ sitic stainless steel, welded by electron beam.) Institut National Polytechnique de Toulouse. 2006. (in French)

[14] Wang, J., Zou, H., Li, C., Zuo, R., Qiu, S., Shen, B. "Relationship of microstructure transformation and hardening behavior of type 17-4 $\mathrm{PH}$ stainless steel." Journal of University of Science and Technology Beijing, Mineral, Metallurgy, Material. 13(3), pp. 235-239. 2006.

https://doi.org/10.1016/S1005-8850(06)60050-9

[15] Bouchouicha, B., Zemri, M., Zaim, A., Chikh, B. O. "Estimation of the energy of crack propagation in different zones of a welded joint by the local technique." International Journal of Fracture. 192(1), pp. 107-116. 2015. https://doi.org/10.1007/s10704-015-9989-1

[16] Miloud, M. H., Bahri, O. C., Ali, B., Mohamed, B., Benattou, B."Effect of the mechanical properties and mode loading on the mechanical behaviour of weldment: a numerical analysis." Materials Research. 16(4), pp. 853-859. 2013. https://doi.org/10.1590/S1516-14392013005000064

[17] Hachim, A. "Numerical study and experimental validation of the mechanisms of damage and cracking of steel S355: application to pressure equipment." PhD Thesis, Faculty of Sciences -Aïn Chock,Casablanca, Marocco. 2013.

[18] Slimane, A., Bouchouicha, B., Benguediab, M., Slimane, S.-A. "Parametric study of the ductile damage by the Gurson-Tvergaard-Needleman model of structures in carbon steel A48-AP." Journal of Materials Research and Technology. 4(2), pp. 217-223. 2015.

https://doi.org/10.1016/j.jmrt.2014.12.011

[19] Bahram, K., Bouchouicha, B., Benguediab, M., Slimane, A. "Admissibility of External Cracks in a Pipeline API X60 Using the SINTAP Procedure." Periodica Polytechnica Mechanical Engineering. 61(4), pp. 261-265. 2017.

https://doi.org/10.3311/ppme.10516

[20] Guedri, A., Boutlidja, R., Djebbar, Y., Merzoug, B. "Interprétation de l'effet du test hydrostatique dans un tube en acier de type API5L-X60." (Interpretation of the effect of the hydrostatic test in a steel tube type API5L-X60.) In: 3ème Conférence Internationale sur la Maintenance et la Sécurité Industrielle, CIMSI'2015, Soukahras, Algeria, Nov. 9-10, 2015. (in French)

[21] Yoshihara, H., Mizuno, H. "Mode I Critical Stress Intensity Factor of Medium-Density Fiberboard Obtained by Single-Edge-Notched Bending Test." Drvna industrija. 65(2), pp. 99-104. 2014. https://doi.org/10.5552/drind.2014.1326 